\title{
Contraceptive implants: current perspectives
}

\author{
This article was published in the following Dove Press journal: \\ Open Access Journal of Contraception \\ 23 September 2014 \\ Number of times this article has been viewed
}

\author{
Sam Rowlands ${ }^{1,2}$ \\ Stephen Searle ${ }^{3}$ \\ 'Centre of Postgraduate Medical \\ Research and Education, School of \\ Health and Social Care, Bournemouth \\ University, Bournemouth, United \\ Kingdom; ${ }^{2}$ Dorset HealthCare, \\ Bournemouth, United Kingdom; \\ ${ }^{3}$ Sexual Health Services, \\ Chesterfield, United Kingdom
}

\begin{abstract}
Progestin-only contraceptive implants are a highly cost-effective form of long-acting reversible contraception. They are the most effective reversible contraceptives and are of a similar effectiveness to sterilization. Pregnancies are rare in women using this method of contraception, and those that do occur must be fully investigated, with an ultrasound scan of the arm and serum etonogestrel level if the implant cannot be located. There are very few contraindications to use of implants, and they have an excellent safety profile. Both acceptability and continuation with the method are high. Noncontraceptive benefits include improvements in dysmenorrhea, ovulatory pain, and endometriosis. Problematic bleeding is a relatively common adverse effect that must be covered in preinsertion information-giving and supported adequately if it occurs. Recognized training for both insertion and removal should be undertaken. Care needs to be taken at both insertion and removal to avoid neurovascular injury. Implants should always be palpable; if they are not, noninsertion should be assumed until disproven. Etonogestrel implants are now radiopaque, which aids localization. Anticipated difficult removals should be performed by specially trained experts.
\end{abstract}

Keywords: contraceptive, subdermal implant, etonogestrel, levonorgestrel, progestin-only, long-acting reversible contraception

\section{Introduction}

This review covers subdermal implants currently in use. Much of the original safety and efficacy research was carried out on the levonorgestrel (LNG) system, Norplant (Wyeth-Ayerst Laboratories, Philadelphia, PA, USA). In high-income countries, ${ }^{1}$ there has been a shift toward using the etonogestrel (ENG) implant because of the greater ease of use of a single rod. However, LNG two-rod systems are extensively used around the world. The scope of this review will include LNG products, but there will be an emphasis on ENG implants. Other products such as Nestorone (Antares Pharma, Ewing, NJ, USA) implants are outside the scope of this review.

This review presents evidence from the world literature. It should be noted that some of the recommendations differ from those contained within the summary of product characteristics of the relevant products.

\section{Classification as a long-acting reversible contraceptive}

It is estimated that almost half of pregnancies in Great Britain either are unplanned or the women are ambivalent about them. ${ }^{2}$ In other high-income countries, between one-third and a half of pregnancies are estimated to be unplanned. Many of these 
unintended pregnancies occur during use of less-effective methods of contraception, such as pills and condoms. Wider uptake of long-acting reversible contraceptive (LARC) methods is expected to reduce unintended pregnancy. Insertion after abortion has been shown to reduce the likelihood of a woman returning for a further abortion by a factor of 16 times compared with those receiving combined pills, injectables, or no method of contraception. ${ }^{3}$

LARCs have been defined in the UK National Institute for Health and Care Excellence guideline as contraceptive methods that require administration less than once per cycle or month. ${ }^{4}$ Included in the category of LARCs are progestinonly subdermal implants (administered every 3-5 years), copper intrauterine devices (mostly administered every 5-10 years), progestin-only intrauterine systems (administered every 3-5 years), progestin-only injectable contraceptives (administered every 8-13 weeks), and combined vaginal rings (require administration every 4 weeks).

In some countries such as the United States, LARCs have a more restricted definition and are confined to subdermal implants and intrauterine devices. ${ }^{5}$

\section{Prevalence of use of implants}

Despite many millions of implants having been inserted around the world, the prevalence of use remains low. Considering that even the surgical method of female sterilization has a prevalence of use of $18 \%$ worldwide, and even as high as $36 \%$ in India, ${ }^{6}$ implants have been slow to take off. For example, in France, only $2.6 \%$ of women younger than 30 years were using an implant in $2010 .^{7}$ In Great Britain, in $2008,1 \%-2 \%$ of women of childbearing age were using the implant, ${ }^{8}$ approximately a quarter of a million women. Countries that have succeeded in raising the prevalence beyond $3 \%$ of women of reproductive age who are married or in a union are Burkina Faso, Colombia, Ethiopia, Norway, and Rwanda. ${ }^{6}$

\section{Brief history}

The first implant to reach the market was Norplant. This had LNG in dry, crystalline form contained within six capsules, each measuring $2.4 \times 34 \mathrm{~mm}$. It was first licensed in 1983 in Finland, with a 5-year lifespan. Continuing research centered on reducing the number of units to facilitate easier insertion and removal. Norplant's successor, Norplant-2 or Jadelle ${ }^{\circledR}$ (Bayer Schering Pharma, Turku, Finland), was approved in the United States in 1996 as a 3-year implant and in 2001 as a 5-year method. Norplant production was discontinued globally in 2008 .
The ENG implant, Implanon ${ }^{\circledR}$ (Merck \& Co, Inc., Whitehouse Station, NJ, USA), was launched in 1999. Its successor, Implanon $\mathrm{NXT}^{\circledR}\left(\mathrm{Nexplanon}^{\circledR}\right)$, with a redesigned applicator, was launched in 2010; it is replacing Implanon in many countries.

\section{Main types of implant Levonorgestrel implants}

LNG implants are two-rod implants inserted using a disposable trocar ${ }^{9}$ in a narrow V-shape. There are two available products: Jadelle (Figure 1) and Sino-implant (11) ${ }^{\circledR}$ (Shanghai Dahua Pharmaceutical Co, Ltd, Shanghai, People's Republic of China). In both implants, each $2.5 \times 43 \mathrm{~mm}$ capsule contains $75 \mathrm{mg}$ LNG. Thin-walled silicone (silastic) tubing encases LNG embedded in a siloxane copolymer. Jadelle was initially licensed for 3 years; this has been extended to 5 years in most countries. Sino-implant (11) is licensed for 4 years (Table 1 ).

Jadelle has been extensively evaluated, together with its predecessor, Norplant. Jadelle is a safe and highly effective method of contraception. ${ }^{10}$ Evaluation of Sino-implant $(11)^{11-13}$ shows it is also a safe and highly effective method.

\section{Etonogestrel implants}

These are solid single rods measuring $2 \times 40 \mathrm{~mm}$ with a special applicator; the newer applicator for Implanon NXT/ Nexplanon is shown in Figure 2. The progestin ENG (formerly called 3-ketodesogestrel) is used. ENG microcrystals $(68 \mathrm{mg})$ are embedded in an ethinyl-vinyl acetate copolymer matrix, covered by a $0.6 \mathrm{~mm}$ rate-controlling ethinyl-vinyl acetate membrane. Implanon NXT/Nexplanon also contains $15 \mathrm{mg}$ barium sulphate; this radiopaque ENG implant is bioequivalent to the nonradiopaque Implanon. ${ }^{14}$

ENG implants are safe and highly effective. ${ }^{15}$ There is no significant difference in pregnancy rates between ENG and LNG implants. ${ }^{16}$

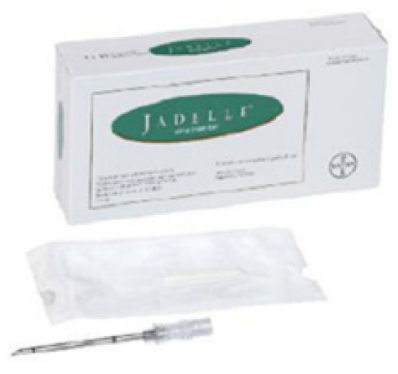

Figure I Jadelle packet showing disposable trocar.

Notes: Picture courtesy Bayer HealthCare; Jadelle ${ }^{\circledR}$ (Bayer Schering Pharma, Turku, Finland). Bayer HealthCare has advised that Jadelle ${ }^{\circledR}$ is not licensed in the UK. 
Table I Characteristics of different contraceptive implants

\begin{tabular}{lllll}
\hline Progestin & $\begin{array}{l}\text { Proprietary } \\
\text { name }\end{array}$ & $\begin{array}{l}\text { Number } \\
\text { of units }\end{array}$ & $\begin{array}{l}\text { Lifespan } \\
\text { according } \\
\text { to license }\end{array}$ & $\begin{array}{l}\text { Countries } \\
\text { registered } \\
\text { in }\end{array}$ \\
\hline LNG & Norplant & Six capsules & 5 years & - \\
LNG & Jadelle & Two rods & 5 years & 47 \\
LNG & Sino-implant (II) & Two rods & 4 years & 19 \\
ENG & Implanon NXT/ & Single rod & 3 years & 80 \\
& Nexplanon & & & \\
\hline
\end{tabular}

Notes: Norplant (Wyeth-Ayerst Laboratories, Philadelphia, PA, USA). Jadelle ${ }^{\circledR}$ (Bayer Schering Pharma, Turku, Finland). Sino-implant (II) (Shanghai Dahua Pharmaceuticals Co., Ltd, Shanghai, China). Implanon NXT ${ }^{\oplus} /$ explanon $^{\circledast}$ (Merck \& Co, Inc., Whitehouse Station, NJ, USA).

\section{Availability and pricing}

LNG implants are included in the World Health Organization's (WHO's) 18th list of essential medicines. ${ }^{17}$ Both Implanon and Jadelle meet the WHO prequalification requirements.

In 2013, more than 6 million implants were shipped to more than 140 low- and middle-income countries around the world, according to the United Nations Population Fund's AccessRH. ${ }^{18}$

ENG and LNG implants are now available at similar prices in low-income countries. Sino-implant (11) is available at approximately US\$8 per unit. A Bill and Melinda Gates Foundation initiative lowered the price of Jadelle to US $\$ 8.50$ per unit as part of an agreement with the manufacturer for the production of at least 27 million units over the next 6 years. The price of Implanon has also been reduced to US\$8.50 in low-income countries.

Essential facts about all three implants can be viewed on the website of the Knowledge for Health (K4Health) Project. ${ }^{19}$ FHI360 provides technical assistance in countries wishing to introduce Sino-implant (11).

\section{Pharmacology Mode of action}

The primary mode of action of all subdermal implants is to prevent ovulation. ${ }^{20,21}$ Secondary modes of action include prevention of sperm penetration of the cervical mucus and prevention of implantation by thinning the endometrium.

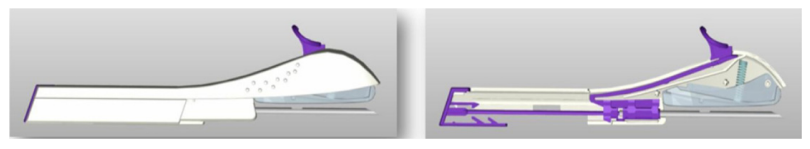

Figure 2 Implanon NXT/Nexplanon applicator.

Notes: Implanon ${ }^{\circledR}$ (Merck \& Co, Inc.). Reproduced with permission of Merck Sharpe \& Dohme B.V., a subsidiary of Merck \& Co., Inc., Whitehouse Station, New Jersey, USA. All rights reserved.

\section{Pharmacokinetics}

As can be seen in Figure 3, plasma levels of ENG sufficient to inhibit ovulation $(>90 \mathrm{pg} / \mathrm{mL})$ are achieved within hours of insertion. Four to 6 months after insertion, plasma levels remain almost constant, with only a gradual decline. This information may be of help when managing women experiencing adverse effects. For example, if the woman has symptoms during the first few months after insertion, she can be told that the hormone levels will gradually fall for the first 4-6 months. If her symptoms are related to ENG, they may improve in this period, and with supportive management, this may prevent premature removal.

After removal, plasma ENG levels fall rapidly, being below the threshold for detection by the assay $(20 \mathrm{pg} / \mathrm{mL})$ within about 4 days.

Release characteristics of LNG implants are generally similar to those of ENG implants, resulting in almost identical pharmacokinetics, with an initial peak and a gradual fall over time. ${ }^{22}$

\section{Drug interactions}

The contraceptive efficacy of the progestin-only implant is reduced by enzyme-inducing drugs such as some antiepileptic drugs, some antibiotics (eg, rifampicin), and antiretroviral therapy. ${ }^{23}$ Implantable contraception should not be initiated in a woman taking long-term interacting drugs. Additional precautions are advised during shortterm use of enzyme-inducing drugs and for 28 days after cessation.

\section{Effectiveness}

A small study indicated that serum levels of ENG higher than $90 \mathrm{pg} / \mathrm{mL}$ will inhibit ovulation in $97 \%$ of women, ${ }^{24}$ these levels are achieved within 8 hours of implant insertion, meaning that effectiveness can be ensured from the day of insertion. Serum ENG concentrations decrease during the 3 years, from just over $1,000 \mathrm{pg} / \mathrm{mL}$ to a little over $100 \mathrm{pg} / \mathrm{mL}$ by the end of year 3 .

Varying body weight is thought to be partly responsible for the wide range of serum levels. Although ovulation is occasionally observed in the third year of use, ${ }^{25}$ the implant remains a highly effective contraceptive throughout this time because of the secondary modes of action. The overall pregnancy rate reported in the National Institute for Health and Care Excellence guideline is less than $0.1 \%$ over the course of 3 years. ${ }^{4}$ For women who have undergone female sterilization, the lifetime percentage rate is $0.5 \%$, and for men undergoing vasectomy, the corresponding figure is $0.05 \%{ }^{26}$ 


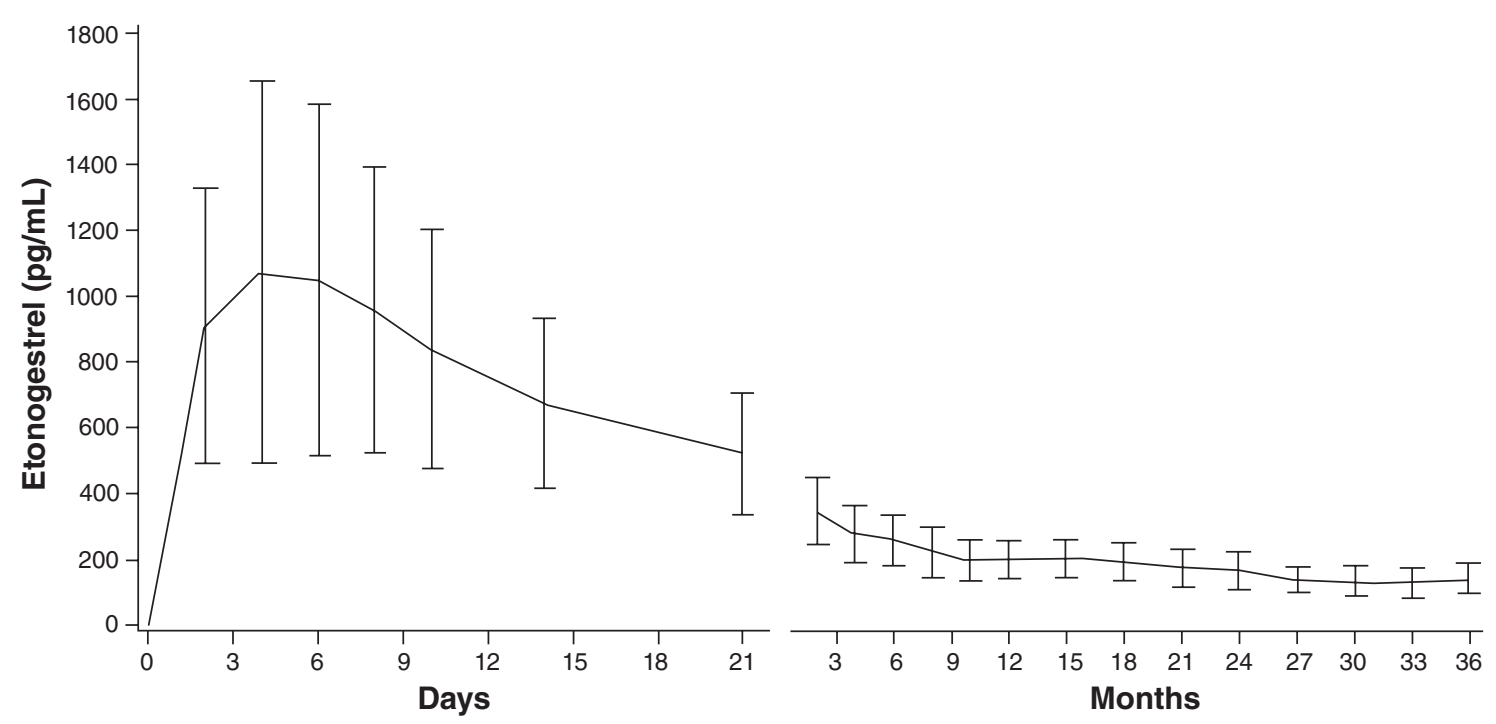

Figure 3 Serum concentration of etonorgestrel $(\mathrm{pg} / \mathrm{ml})$ over time during 3 years of Nexplanon ${ }^{\circledR}$ use.

Notes: Nexplanon ${ }^{\circledR}$ (Merck \& Co., Inc.). Reproduced with permission of Merck Sharp \& Dohme B.V., a subsidiary of Merck \& Co., Inc., Whitehouse Station, New Jersey, USA. All rights reserved.

Several researchers have raised the question of whether reduced ENG levels in obese women may increase the failure rate, especially in the third year of use. ${ }^{27}$ No large studies have been conducted to answer this question. The overall numbers of implant failures are very low, and no definite failures have been reported in obese women. The WHO Medical Eligibility Criteria give obesity as a condition for which there is no restriction of use for the implant. ${ }^{28}$ The Faculty of Sexual and Reproductive Healthcare Clinical Effectiveness Unit also advises that there is no direct evidence to support earlier replacement in overweight women. ${ }^{15}$

\section{Medical eligibility}

There are no age restrictions for use of contraceptive implants, which can therefore be a choice for women of any reproductive age. There are a few medical conditions for which the risks of implant use generally/usually outweigh the advantages, as defined by the WHO Medical Eligibility Criteria. ${ }^{28}$ These include:

- severe hepatic disease, such as decompensated cirrhosis, hepatocellular adenoma, or malignant hepatoma, or systemic lupus erythematosus with positive (or unknown) antiphospholipid antibodies;

- women taking liver enzyme-inducing drugs (see "Drug interactions");

- where a woman develops ischemic heart disease or stroke while using an implant, it is recommended that the implant be discontinued, and for women with preexisting ischemic heart disease or stroke, the benefits of implant use would be greater than the risks;

- current or past history of breast cancer, which is a contraindication to implant use; and

- in cases of undiagnosed vaginal bleeding, the cause should be evaluated before inserting an implant.

There is no strong evidence of harm for women with any medical conditions other than these. The UK Medical Eligibility Criteria cites eight references supporting no adverse effects of implants on lactation or infant development for breastfeeding women who are less than 6 weeks postpartum, classifying such women as category $1 .{ }^{29}$ Once acute thromboembolism is being treated with anticoagulants, this is category $2 . .^{29,30}$

All reasonable efforts should be made to exclude pregnancy at the time of insertion, although in the small number of women who have delivered a baby after implant use during the pregnancy, there is no evidence of an increased risk of congenital abnormalities. ${ }^{15}$

\section{Insertion}

\section{Timing of insertion}

An implant can be inserted at any time in a woman's cycle, providing attempts have been made to exclude pregnancy. ${ }^{15}$ Up to day 5 after the start of normal menstruation, it can be assumed that the pregnancy risk is negligible. If an implant has been inserted in a woman in whom there is any doubt about whether her last menstrual period was normal, a pregnancy test is advisable 3 weeks later. 
After day 5 of the cycle, an implant can be inserted if the woman has abstained from sex or used another method of contraception reliably and the woman is prepared to take the small risk of failure of that method. In this situation, alternative contraception should be used for the first week after insertion, although the implant will start to be effective before this.

When a woman has chosen an implant, rather than awaiting the onset of the next menses (during which time she may become pregnant with or without use of a less-reliable method), "quick-starting" an implant is preferable. ${ }^{31}$ This involves inserting the implant at the time of first presentation after attempting to exclude pregnancy (by taking a sexual and contraceptive history and performing a pregnancy test if appropriate). Additional careful contraceptive use is recommended for the first week. There should be a low threshold for a repeat pregnancy test 3 weeks after the last unprotected sex. This test is especially important if the implant is quickstarted at the same time emergency hormonal contraception is used. If ulipristal acetate has been taken, careful use of barrier contraception should be extended to 2 weeks.

Postpartum, if an implant can be inserted within 21 days, there is no need for extra precautions. ${ }^{15}$ If the woman is fully breastfeeding up to 6 months postpartum and is amenorrheic (lactational amenorrhea method), it can be assumed she is not currently pregnant. Similarly, after first or second trimester abortion, the implant would act immediately if inserted within 5 days.

\section{Insertion technique}

Care should be taken to avoid deep insertion into muscle or injury to nerves or blood vessels. ${ }^{15}$ The applicator should, initially, be angled at $30^{\circ}$ to the skin and then lowered to a horizontal position as soon as the needle pierces the dermis. Once the needle has pierced the skin, it is common for the needle tip to be somewhat too deep immediately. To overcome this problem, careful withdrawal of the needle until the bevel just becomes visible before advancing the needle ensures the implant is being inserted into the superficial subdermal plane. Tenting of the skin is needed with Implanon NXT/Nexplanon, even though there is a mechanism in the applicator to set the depth below the skin surface to about $2 \mathrm{~mm}$. Immediately after insertion, the health professional should verify the presence of the implant by palpation and should ask the woman to do the same. Documentation should include which arm the implant has been inserted into, that the rod could be felt in the arm, and any difficulties encountered.

\section{Complications of insertion}

Complications of insertion are almost entirely minor. ${ }^{32}$ It is relatively common to see some minimal bruising after insertion. Some women experience tenderness, pain, redness, or irritation. In a review of all trials of Implanon, swelling at the insertion site occurred in $0.5 \%$ of insertions, redness in $0.3 \%$, and pain in $1.9 \%$ of cases. ${ }^{33} \mathrm{~A}$ study of Nexplanon showed an incidence of swelling or redness of $4.7 \%{ }^{34}$ Postinsertion wound infection (cellulitis) is not reported in trials of ENG implants, but occasional cases of wound infection needing treatment with antibiotics are seen.

\section{Site of insertion}

A standard site for insertion makes it easier for clinicians to locate the implant wherever in the world the woman presents for removal. It was previously recommended that the insertion site for the ENG implant (as had been the case for Norplant) be in the groove between the biceps and triceps muscles. The manufacturer then changed the summary of product characteristics to recommend insertion $8-10 \mathrm{~cm}$ above the medial epicondyle of the humerus. The summary of product characteristics for Implanon NXT states that the implant should be inserted at the inner side of the upper arm to avoid the large blood vessels and nerves that lie deeper in the connective tissue between the biceps and triceps muscles. The critical point is that implants must be inserted superficially, that is, immediately subdermally, so risk of neurovascular damage at insertion and removal is avoided.

\section{Timing of repeat insertion}

Up to 3 years after insertion, the implant can be replaced without additional precautions. There are some isolated reports of women who have not become pregnant when the implant has been in situ beyond 3 years. ${ }^{35}$ However, with no systematic evidence of low pregnancy rates beyond 3 years, it is recommended that extra contraception be used until replacement in this situation.

\section{Local anesthesia}

Most clinicians offer women a small injection of local anesthetic at insertion and removal sites. The site should be anesthetized, using lidocaine $1 \%$ or $2 \%$. Lidocaine with adrenaline 1:200,000 can be used instead, to reduce bleeding (eg, for deep implant removal or women with bleeding disorders [outside product license]).

Women who are allergic to local anesthetic could be advised that the implant insertion needle is similar in size 
to a blood donation needle, for which local anesthetic is usually not given. For severely needle-phobic women, ethyl chloride spray or topical local anesthetic cream are alternatives, although these have not been formally studied for implant use.

\section{Noncontraceptive benefits}

Improvement in dysmenorrhea and ovulatory pain has been noted with implants ${ }^{36}$ when there is no underlying pathology. Small studies suggest an improvement in endometriosis, but implantable contraception cannot as yet be recommended as a treatment for this. ${ }^{37}$

\section{Tolerability and longer-term risks Bone mineral density}

Compared with intrauterine device users, one study found no difference in bone mineral density in ENG implant users. ${ }^{38}$ Studies of forearm bone density have reported reduced bone mineral density in ENG and LNG implant users. $^{39,40}$ It is not known whether these differences are clinically significant. As ovarian activity is not fully suppressed, and natural estradiol levels are maintained, it is reasonable to conclude that there is no clinically significant loss of bone mineral density.

\section{Risks}

Unlike with combined hormonal methods, and as with other progestin-only methods, there is not thought to be any increased risk of venous thromboembolism with implant use, but few large studies have been conducted. ${ }^{15}$

Some studies have looked at the risk of myocardial infarction and stroke for implant users. There does not appear to be any increased risk; ${ }^{15}$ however, there is very little evidence relating to high-risk women, and these events are rare in women of reproductive age.

In relation to breast cancer, there is little specific evidence. A case-control study showed no increased risk of breast cancer in a small sample of women using implantable contraception. ${ }^{41}$

\section{Effect on bleeding: management of problematic bleeding}

Bleeding problems are one of the more likely reasons for early discontinuation of the method. ${ }^{15}$ Less than one-quarter of women using the ENG implant will have regular bleeds. Infrequent bleeding is the most common pattern (in approximately one-third of the women with the implant), around one-fifth of women experience no bleeding, and approximately one-quarter have prolonged or frequent bleeding. ${ }^{42}$ As these bleeding adverse effects are common, it is important to warn women of the likelihood of unpredictable bleeding before the time of insertion. They should be advised to seek help if it does occur and is troublesome, as there are a number of management options to support women experiencing unacceptable bleeding.

The first step in management is to consider sexually transmitted infections and gynecological pathology. When reasonable steps have been taken to exclude these and simple reassurance about the bleeding has been insufficient, addition of combined hormonal contraception (CHC) if the woman has no contraindications to estrogen is the recommended first step. ${ }^{15} \mathrm{CHC}$ may be used, for example, for 3 months initially, either in the usual cyclic manner or continuously without a hormone-free interval, with the aim of creating a no-bleed pattern. Such use is outside the product license but is supported by expert opinion. ${ }^{43}$ Some women benefit from longer-term $\mathrm{CHC}$ use in conjunction with the implant. They often appreciate the high effectiveness of the implant, combined with the control of bleeding provided by the CHC. For women who are not eligible to use $\mathrm{CHC}$, alternative strategies such as the addition of oral or injectable progestin may be effective; this can be considered on an individual basis, although no studies have examined this form of treatment. If unacceptable bleeding occurs toward the end of the implant's licensed duration, early replacement of the implant may be considered as an alternative to the above strategies. Other treatments that have been advocated include the addition of mefenamic acid (particularly where dysmenorrhea is also a feature) or short-term or intermittent tranexamic acid, doxycycline, or mifepristone. ${ }^{15}$ The latter has the theoretical concern of reducing the implant's effectiveness, as it blocks progesterone receptors. The aim of all these regimens is to alleviate bleeding adverse effects, and so support women's continuation of the method.

\section{Reactions of young people to bleeding problems}

Qualitative research has been carried out by Hoggart and Newton ${ }^{44}$ on young people's reactions to contraceptive implants. They describe a "tipping point," beyond which a young woman can no longer tolerate irregular bleeding and requests removal. Discussions with such a woman about treating the bleeding or persisting with the method are unlikely to be well-received. It appears that a bad experience with bleeding problems from an implant at a young age can have a marked and possibly permanent effect on the acceptability of the method to them. 


\section{Skin reactions}

Apart from common local reactions to the insertion procedure (see "Insertion technique"), longer-term skin reactions are possible.

There are case reports of skin atrophy ${ }^{45,46}$ at the site of subdermal implants, and fibrosis around the implant has also been documented. Fibrosis is likely to be greater after a wound infection. Anecdotal reports have been received of implants being sited too superficially, causing pain and altered sensation.

There also have been descriptions of an inflammatory reaction around an implant. The features of these reports include a transient period of apparent improvement of local reaction around the implant site. This may be followed by recurrence, culminating in skin breakdown at the insertion site with extrusion of the implant. ${ }^{47}$ These cases do not seem to be infections, as microbiological swabs are usually negative.

Finally, there is a report that secondary skin infection can occur in those with eczema. ${ }^{48}$

\section{Other possible adverse effects}

There have been reports of changes in weight, mood, and libido when using the progestin-only implant; however, there is no evidence of causal associations. ${ }^{15}$ The same applies to headache: there is no restriction on implant use for women with migraine with aura. Even if migraine with aura develops on the implant, the benefits of the implant usually outweigh the risks. ${ }^{30}$

Acne may improve, appear for the first time, or worsen during use of an implant. ${ }^{15}$ Some women whose skin was helped by the estrogen in CHCs may relapse when $\mathrm{CHCs}$ are changed to the implant.

\section{Adverse effects Impalpable implants}

There is a consensus that impalpable implants were placed deeply at the time of insertion, rather than being displaced subsequently, because of migration. ${ }^{49,50}$ Deep insertion may be more likely to occur in thin women with scant subcutaneous tissue. ${ }^{51}$ Weight gain subsequent to insertion may make an implant less easy to palpate, and thus more difficult to remove..$^{52}$ These weight-related factors can lead to a removal procedure that is more technically challenging.

Difficult removals can also be associated with wound infection complicating the insertion procedure because of resultant scar tissue formation. In general, it is not thought that a rod can migrate more than about $2 \mathrm{~cm}$ if the correct subdermal insertion procedure is followed and carried out by a properly trained clinician. ${ }^{53}$

At insertion, the clinician should check that the implant is palpable. The woman should be asked to palpate it as well. If it is not palpable, the implant should not be assumed to have been inserted deeply. Until proved otherwise, it should be assumed that a noninsertion has occurred and the woman should be advised to use additional precautions or avoid intercourse until investigations confirm the presence of the implant.

When a woman presents at a later date with an impalpable implant, exploratory surgery without ascertainment of the precise location of the implant should be avoided. ${ }^{15}$ Highfrequency linear array ultrasound is the first-line imaging technique for locating nonpalpable or deep implants. If the implant is not easily identified with ultrasound, both arms should be examined for insertion site scars. Barium sulfate has been added to the Implanon NXT/Nexplanon rod to make it radiopaque. This makes it visible on X-ray and computed tomography scans, in addition to ultrasound and magnetic resonance imaging. X-ray can therefore be used to investigate the presence/absence of an impalpable Implanon NXT/ Nexplanon that cannot be found using ultrasound.

Removal should not be attempted without precise localization and the appropriate skills. ${ }^{54}$ In the United Kingdom, there are a number of specialists trained in deep implant removals. Sexual and reproductive health services should be able to provide information on the nearest specialist and local referral pathways. If an implant remains undetectable despite imaging, the manufacturer can send instructions for a blood ENG assay. All requests must be discussed in advance with the manufacturer's medical department. If ENG is identified in the sample, health professionals may consider magnetic resonance imaging for those with a nonradiopaque implant or $\mathrm{X}$-ray with a radiopaque implant. If no ENG is detected when the implant is within 3 years of insertion, it can be assumed that there is no implant present in the body. However, there have been reports of false-positive ENG assays, and certain drugs may interfere with the result.

In summary, women with impalpable implants should be referred to an expert in difficult implant removals.

\section{Noninsertion}

Cases of noninsertion have been reported from pharmacovigilance, spontaneous reporting, and analysis of medico-legal cases. ${ }^{55}$ These cases are associated only with the single-rod implants in which the rod is contained 
within an applicator. An applicator redesign from Implanon to Implanon NXT (Nexplanon) was launched in 2010, but noninsertion has still been reported with the new version. As a result of human factors, ${ }^{56}$ the rod is not delivered into the arm during the insertion procedure, and either the clinician fails to palpate the arm or, when palpated, the presence of the rod is mistakenly confirmed. These cases most often present as an unexpected pregnancy. Investigations reveal no implant in the arm and an absence of ENG in the blood.

\section{Neurovascular injury}

At the level of the upper arm used for implant insertion (one third of the way up the upper arm), a neurovascular bundle runs near the biceps/triceps groove and only a few millimeters deep to the fascia. It contains the brachial artery, basilic vein, median nerve, ulnar nerve, and medial cutaneous nerve of the forearm. In 2008, the manufacturer revised the recommended site for insertion, deleting the previous advice to insert implants over the groove. The risk of neurovascular injury is greater in slim women if the implant is inserted even slightly too deep. This is because there is so little subcutaneous fat that the muscle fascia is easily breached if the inserter needle is not immediately subdermal. Injuries have been reported to all five structures in the neurovascular bundle ${ }^{57,58}$ and to the musculocutaneous nerve. ${ }^{59}$ Nerve injury is far more likely to occur during removal procedures. Some cases of nerve injury have resulted in permanent sensory disturbance needing surgical exploration and neurolysis.

Injury to vascular structures has been reported only at insertion. In one case, disappearance of an implant with positive blood ENG was thought to be explained by embolism into the lung. ${ }^{60}$

\section{Fractured/bent implants}

Fracturing or bending of rods was first reported with ENG implants in 2003; ${ }^{61}$ there have been occasional case reports since. ${ }^{62-64}$ Little is known about the reasons why implants bend or break. The authors suspect the main underlying cause is the user "playing" or "fiddling" with the implant. ${ }^{65}$ Other possible mechanisms are strenuous upper arm exercise, manual occupations, or trauma (eg, being gripped forcibly at the site of the implant).

A common approach to ENG implants in which a break in the membrane is suspected is to replace or remove them. Rekers has stated emphatically that the release characteristics of the ENG will not be significantly altered by such a break. ${ }^{66}$ Cases can be managed individually; it would appear that automatic replacement is not necessary for ENG implants.
Replacement in an individual who continues to play with the implant or pursue a heavy manual job is probably futile. Replacement on account of a woman's anxiety when damaged may be justified, depending on the level of the anxiety.

According to the manufacturer, breakage or bending of Jadelle implants has not been reported in clinical studies of use of Jadelle involving approximately 1,400 women. There appears to be no other information available; for example, from postmarketing surveillance. The approach offered here to bent or broken ENG implants cannot be applied to LNG rods. Broken LNG implants might possibly speed up release of the LNG, thereby reducing their lifespan, and so replacement is necessary.

\section{Removal}

Reasons for requests for early implant removal should be discussed with each individual woman. ${ }^{15}$ Supportive management should be offered to those experiencing problems with the implant. There is no need for additional precautions or abstinence before removal of an implant, providing the removal occurs within its lifespan. After removal of a progestin-only implant, effective contraception is required immediately if pregnancy is not desired.

If, on palpation, a rod is thought to be close to the brachial artery, removal should not be attempted and referral should be made to an upper limb surgeon or an interventional radiologist. Similarly, removal attempts should be stopped if there is any indication of sensory disturbance. Removals under general anesthesia are less safe, as sensory disturbance cannot be reported by the woman.

\section{Etonogestrel implants}

Future contraceptive needs should be discussed. The implant should be palpated before preparing equipment, and the distal end of the implant (the end closest to the elbow) should be easily visible when pressure is applied to the proximal end. At the same time, if the skin is pushed under the distal end, this will cause the distal end to pop up. Appropriate local anesthesia should be administered before removal. A small longitudinal incision should be made through the full thickness of the skin, up against the distal end of the implant. It should then be possible to push the implant fully or partially out of the incision. It is usually necessary to incise the "capsule" of connective tissue that forms around implants soon after insertion. This is known as the "pop-out technique"; 67 fine mosquito forceps inserted into the skin incision can be used if necessary. 


\section{Levonorgestrel implants}

LNG implants are best removed using the modified U-technique developed for Norplant. ${ }^{68}$ An incision is made between the implants at a point midway between proximal and distal tips. Modified vasectomy ring forceps are used to assist removal.

With extensive international travel and migration, clinicians may be asked to remove a product they themselves are not familiar with. The last Norplants to have been inserted expired in 2013 (or will expire in 2015 if a 7-year lifespan is assumed ${ }^{69}$ ), so there will be few remaining removals needed for this six-capsule implant. It is particularly important that women with a two-rod implant in situ have both rods removed in countries where only single-rod implants are on the market. Removals should only be undertaken by clinicians who are competent in procedures specific to the product.

\section{Replacement}

If the woman wishes to continue with an implant as her contraceptive method, a replacement implant may be inserted, using the same incision through which the previous implant was removed. ${ }^{15}$ As the new implant will be released a few millimeters higher each time, there may be a time when a new implant needs to be inserted in a distal direction to avoid its placement too high in the arm. The implant also can be inserted into the opposite arm. Some clinicians place a limit on the number of insertions into the same site because of the possibility of skin atrophy around an implant. If the previous implant was incorrectly sited, a new site should be used. Additional contraceptive precautions are not required if the implant is replaced within its lifespan. Eligible women can use subdermal implants throughout their reproductive years, and there is no maximum number of implants a woman can use.

\section{Training}

In an attempt to prevent complications of insertion and removal and to ensure women are given adequate information to make an informed choice regarding implants, structured training is recommended. Clinicians providing contraception should be able to advise women about implants and either offer an implant service themselves or make simple arrangements for implant insertion and removal. In the United Kingdom, those providing implants should be trained in the equivalent of the Faculty of Sexual and Reproductive Healthcare Letter of Competence in Subdermal Contraceptive Implant Techniques. Skills should be maintained such as by the equivalent of the Faculty of Sexual and Reproductive Healthcare recertification guidelines and attending regular updates.

\section{Aftercare and follow-up Aftercare}

Mild bruising is common after insertion or removal because of superficial venous damage. ${ }^{15}$ This should resolve spontaneously. Paper sutures are a convenient way of bringing the skin edges together after removal of an implant to minimize scarring. A sterile dressing should be applied and the wound kept dry for 48 hours after the procedure. A pressure bandage may also be applied after removal. Paper sutures should be left until wound edges are adherent, which normally takes up to a week. Women should be advised to seek medical advice if they develop signs of complications, especially wound infection.

\section{Follow-up}

Routine follow-up of women who have had an implant inserted is not needed. ${ }^{15}$

Women who are quick-started with the implant, for example, after administration of emergency contraception, should be advised to have a pregnancy test performed 3 weeks after the last episode of unprotected sexual intercourse.

Progestin-only implants should always be palpable by the woman. Women should be advised to return if they cannot feel their implant, there is a bend or kink in the implant, the implant feels as if it has broken, or there are any changes to the skin or pain around the site of the implant. If a woman develops any medical problems or starts any medication that may affect her implant, the use of the method should be reviewed. Women should be encouraged to return at any time to discuss problems experienced (eg, problematic bleeding).

\section{Pregnancy with an implant in situ}

In addition to true method failure, possible reasons for implant failure are drug interactions, method insertion failure, or failure to assess the risk of pregnancy at the time of insertion. ${ }^{15}$ Unless a woman is requesting an abortion, it is recommended that if a pregnancy occurs while using the progestin-only implant, the implant be removed. There is no evidence of harm to the woman, the progress of her pregnancy, or the fetus if pregnancy occurs while using an implant. ${ }^{15}$ An implant can be inserted at the time of surgical abortion or immediately after a medical abortion. Unlicensed insertion of a progestin-only implant before abortion would be a matter of clinical judgement, taking into account personal preference and the likelihood of the woman changing her mind. 


\section{Acceptability and continuation}

Retrospective studies have estimated 2-year continuation rates for ENG implants at $50 \%-75 \% .^{70-73}$ In the Contraceptive CHOICE Project prospective cohort study in the United States, $79 \%$ of the women who chose implants were satisfied and $83 \%$ were continuing the method at 1 year. ${ }^{74}$ At 2 years, continuation rates had fallen to $69 \%{ }^{75}$ Among women in four European countries, satisfaction with the method was $66 \%$ in those opting for implants, and the continuation rate was $86 \%$ at 1 year; ${ }^{76}$ at 2 years in this study, satisfaction was slightly higher, at $70 \%$, and continuation was $83 \% .{ }^{77}$ In an Australian 3 -year study, $85 \%$ of women were continuing at 1 year, $70 \%$ at 2 years, and $53 \%$ at 3 years. ${ }^{78}$ In the latter three studies, the implant came closely behind the intrauterine system with respect to both satisfaction and continuation. It needs to be stressed how much higher continuation rates with implants are compared with combined hormonal contraception; they are also significantly higher than rates for injectables.

\section{Return to fertility}

Ovulation returns within 3 weeks of implant removal in more than $90 \%$ of women. ${ }^{79}$ Return to fertility after discontinuation of implants is no different from other contraceptive methods, excluding injectables. ${ }^{80}$ Women can be advised that there is no delay in return of fertility after implant removal.

\section{Cost-effectiveness}

As mentioned earlier, increasing the uptake of long-acting reversible methods of contraception such as the progestin-only implant is expected to reduce unintended pregnancies. ${ }^{4}$ Pregnancies, whether delivered, miscarried, terminated, or ectopic, all have associated costs. Pregnancies averted result in cost savings. Use of the progestin-only implant is cost-effective at 1 year of use. ${ }^{81}$ The implant is more cost-effective than contraceptive pills ${ }^{82}$ or injectable methods. The implant also is more cost-effective than the LNG intrauterine system up to 3 years of use. ${ }^{4}$

\section{Acknowledgment}

Bayer HealthCare has advised that Jadelle ${ }^{\circledR}$ is not licensed in the UK.

\section{Disclosure}

Both authors have received fees for consultancy and provision of training from the manufacturers of contraceptive implants. The authors report no other conflicts of interest in this work.

\section{References}

1. The World Bank. How We Classify Countries. Washington, DC: The World Bank. Available from: http://data.worldbank.org/about/countryclassifications. Accessed March 28, 2014.
2. Wellings $\mathrm{K}$, Jones $\mathrm{KG}$, Mercer $\mathrm{CH}$, et al. The prevalence of unplanned pregnancy and associated factors in Britain: findings from the third National Survey of Sexual Attitudes and Lifestyles (Natsal-3). Lancet. 2013;382(9907):1807-1816.

3. Cameron ST, Glasier A, Chen ZE, Johnstone A, Dunlop C, Heller R. Effect of contraception provided at termination of pregnancy and incidence of subsequent termination of pregnancy. BJOG. 2012;119(9):1074-1080.

4. National Collaborating Centre for Women's and Children's Health. LongActing Reversible Contraception. London: National Institute for Health and Care Excellence; 2005. Available from: http://publications.nice. org.uk/long-acting-reversible-contraception-cg30. Accessed April 3, 2014.

5. Finer LB, Jerman J, Kavanaugh ML. Changes in use of long-acting contraceptive methods in the United States, 2007-2009. Fertil Steril. 2012;98(4):893-897.

6. United Nations, Department of Economic and Social Affairs Population Division, Fertility and Family Planning Section. World Contraceptive Use 2012: Survey-Based Observations (1950-2014). New York: United Nations. Available from: http://www.un.org/esa/population/publications/ WCU2012/MainFrame.html. Accessed April 3, 2014.

7. Moreau C, Bohet A, Hassoun D, Teboul M, Bajos N; FECOND Working Group. Trends and determinants of use of long-acting reversible contraception use among young women in France: results from three national surveys conducted between 2000 and 2010. Fertil Steril. 2013;100(2):451-458.

8. Lader D. Opinions Survey Report No 41. Contraception and Sexual Heath, 2008/09. Newport, United Kingdom: Office for National Statistics; 2009. Available from: http://www.ons.gov.uk/ons/search/index. $\mathrm{html}$ ? pageSize $=50 \&$ sortBy $=$ none $\&$ sortDirection $=$ none \&newquery $=$ opinions + survey + report $+\mathrm{No}+41+$ contraception. Accessed April 3, 2014.

9. Steiner MJ, Boler T, Obhai G, Hubacher D. Assessment of a disposable trocar for insertion of contraceptive implants. Contraception. 2010; 81(2):140-142.

10. Sivin I, Nash H, Waldman S. Jadelle ${ }^{\circledR}$ Levonorgestrel Rod Implants: A Summary of Scientific Data and Lessons Learned from Programmatic Experience. New York: Population Council; 2002. Available from http://www.popcouncil.com/pdfs/jadelle_monograph.pdf. Accessed April 3, 2014.

11. Steiner MJ, Lopez LM, Grimes DA, et al. Sino-implant (II) - a levonorgestrel-releasing two-rod implant: systematic review of the randomized controlled trials. Contraception. 2010;81(3):197-201.

12. Feldblum PJ, Hanitriniaina O, Lendvay A, et al. Performance of Sino-implant (II) in routine service delivery in Madagascar. Contraception. 2013;88(1):103-108.

13. Lendvay A, Otieno-Masaba R, Azmat SK, et al. Effectiveness, safety and acceptability of Sino-implant (II) during the first year of use: results from Kenya and Pakistan. Contraception. 2014;89(3):197-203.

14. Schnabel P, Merki-Feld GS, Malvy A, Duijkers I, Mommers E, van den Heuvel MW. Bioequivalence and X-ray visibility of a radiopaque etonogestrel implant versus a non-radiopaque implant: a 3-year, randomized, double-blind study. Clin Drug Investig. 2012;32(6):413-422.

15. Faculty of Sexual and Reproductive Healthcare. Progestogen-only Implants. London: Faculty of Sexual and Reproductive Healthcare; 2014. Available from: http://www.fsrh.org/pdfs/CEUGuidanceProgestogenOnlyImplants.pdf. Accessed April 3, 2014.

16. Power J, French R, Cowan F. Subdermal implantable contraceptives versus other forms of reversible contraceptives or other implants as effective methods for preventing pregnancy. Cochrane Database Syst Rev. 2007;3:CD001326.

17. WHO Model List of Essential Medicines [webpage on the Internet]. Geneva: World Health Organization; 2013. [Revised October, 2013]. Available from: http://www.who.int/medicines/publications/essentialmedicines/ 18th_EML_Final_web_8Jul13.pdf. Accessed May 16, 2014.

18. AccessRH [homepage on the Internet]. Copenhagen: United Nations Population Fund. Available from: http://www.myaccessrh.org/. Accessed May 16, 2014. 
19. Implants Toolkit [webpage on the Internet]. Baltimore: US Agency for International Development: The Knowledge for Health (K4Health) Project. Available from: http://www.k4health.org/toolkits/implants. Accessed May 16, 2014.

20. Davies GC, Feng LX, Newton JR, Van Beek A, Coelingh-Bennink HJ. Release characteristics, ovarian activity and menstrual bleeding pattern with a single contraceptive implant releasing 3-ketodesogestrel. Contraception. 1993;47(3):251-261.

21. Mäkäräinen L, van Beek A, Tuomivaara L, Asplund B, Coelingh Bennink H. Ovarian function during the use of a single contraceptive implant: Implanon compared with Norplant. Fertil Steril. 1998;69(4): 714-721.

22. Croxatto HB. Progestin implants for female contraception. Contraception. 2002;65(1):15-19.

23. Faculty of Sexual and Reproductive Healthcare. Drug Interactions with Hormonal Contraception. London: Faculty of Sexual and Reproductive Healthcare; 2011. Available from: http://www.fsrh.org/ pdfs/CEUguidancedruginteractionshormonal.pdf. Accessed April 3 , 2014.

24. Díaz S, Pavez M, Moo-Young AJ, Bardin CW, Croxatto HB. Clinical trial with 3-keto-desogestrel subdermal implants. Contraception. 1991;44(4):393-408

25. Croxatto HB. Mechanisms that explain the contraceptive action of progestin implants for women. Contraception. 2002;65(1):21-7.

26. Clinical Effectiveness Unit. Male and Female Sterilisation. London: Faculty of Sexual and Reproductive Healthcare. In press 2014.

27. Huber J, Wenzl R. Pharmacokinetics of Implanon ${ }^{\circledR}$. An integrated analysis. Contraception. 1998;58(Suppl 6):85S-90S.

28. World Health Organization. Medical Eligibility Criteria for Contraceptive Use. 4th ed. Geneva: World Health Organization; 2010.

29. Faculty of Sexual and Reproductive Healthcare. UK Medical Eligibility Criteria for Contraceptive Use. London: Faculty of Sexual and Reproductive Healthcare; 2009. Available from: http://www.fsrh.org/ pdfs/UKMEC2009.pdf. Accessed April 3, 2014

30. Curtis KM. US medical eligibility criteria for contraceptive use. Morb Mortal Wkly Rep. Epub May 28, 2010.

31. Faculty of Sexual and Reproductive Healthcare. Quick Starting Contraception. London: Faculty of Sexual and Reproductive Healthcare; 2010. Available from: http://www.fsrh.org/pdfs/CEUGuidanceQuickSt artingContraception.pdf. Accessed April 3, 2014.

32. Brache V, Faundes A, Alvarez F, Cochon L. Nonmenstrual adverse events during use of implantable contraceptives for women: data from clinical trials. Contraception. 2002;65(1):63-74.

33. Mascarenhas L. Insertion and removal of Implanon ${ }^{\circledR}$. Contraception. 1998;58(Suppl 6):79S-83S.

34. Mansour D, Mommers E, Teede H, et al. Clinician satisfaction and insertion characteristics of a new applicator to insert radiopaque Implanon: an open-label, noncontrolled, multicenter trial Contraception. 2010;82(3):243-249.

35. Kiriwat O, Patanayindee A, Koetsawang S, Korver T, Bennink HJ. A 4-year pilot study on the efficacy and safety of Implanon, a single-rod hormonal contraceptive implant, in healthy women in Thailand. Eur $J$ Contracept Reprod Health Care 1998;3(2):85-91.

36. Shokeir T, Amr M, Abdelshaheed M. The efficacy of Implanon for the treatment of chronic pelvic pain associated with pelvic congestion: 1-year randomized controlled pilot study. Arch Gynecol Obstet. 2009;280(3):437-443.

37. Royal College of Obstetricians and Gynaecologists. The Investigation and Management of Endometriosis. Greentop guideline 24. London: RCOG; 2006.

38. Beerthuizen R, van Beek A, Massai R, Mäkäräinen L, Hout J, Bennink HC. Bone mineral density during long-term use of the progestagen contraceptive implant Implanon ${ }^{\circledR}$ compared to a non-hormonal method of contraception. Hum Reprod. 2000;15(1):118-122.

39. Monteiro-Dantas C, Espejo-Arce X, Lui-Filho JF, Fernandes AM, Monteiro I, Bahamondes L. A three-year longitudinal evaluation of the forearm bone density of users of etonogestrel- and levonorgestrelreleasing contraceptive implants. Reprod Health. 2007;4:11.
40. Pongsatha S, Ekmahachai M, Suntornlimsiri N, Morakote N, Chaovisitsaree S. Bone mineral density in women using the subdermal contraceptive implant Implanon for at least 2 years. Int J Gynecol Obstet. 2010;109(3):223-225.

41. Strom BL, Berlin JA, Weber AL, et al. Absence of an effect of injectable and implantable progestin-only contraceptives on subsequent risk of breast cancer. Contraception. 2004;69(5):353-360.

42. Mansour D, Korver T, Marintcheva-Petrova M, Fraser IS. The effects of Implanon ${ }^{\circledR}$ on menstrual bleeding patterns. Eur J Contracept Reprod Health Care. 2008;13 Suppl 1:13-28.

43. Faculty of Sexual and Reproductive Healthcare. The Management of Unscheduled Bleeding in Women Using Hormonal Contraception. London: Faculty of Sexual and Reproductive Healthcare; 2009. Available from: http://www.fsrh.org/pdfs/unscheduledbleedingmay09. pdf. Accessed April 3, 2014.

44. Hoggart L, Newton VL. Young women's experiences of side-effects from contraceptive implants: a challenge to bodily control. Reprod Health Matters. 2013;21(41):196-204.

45. Chadha-Gupta A, Moss A. Fat atrophy at the site of a subdermal contraceptive implant. J Fam Plann Reprod Health Care. 2007;33(2): 123-124.

46. Lindsay P. Localised lipoatrophy at the site of Implanon ${ }^{\circledR}$ insertion. J Fam Plann Reprod Health Care. 2009;35(4):266.

47. Chaudhry F. Adverse reaction to Nexplanon ${ }^{\circledR}$. J Fam Plann Reprod Health Care. 2013;39(3):231-232.

48. Partridge R, Bush J. Infections post-Nexplanon ${ }^{\circledR}$ insertion. J Fam Plann Reprod Health Care. 2013;39(4):309-310.

49. Walling M. How to remove impalpable Implanon ${ }^{\circledR}$ implants. $J$ Fam Plann Reprod Health Care. 2005;31(4):320-321.

50. Singh M, Mansour D, Richardson D. Location and removal of non-palpable Implanon ${ }^{\circledR}$ implants with the aid of ultrasound guidance. J Fam Plann Reprod Health Care. 2006;32(3):153-156.

51. Mansour D, Fraser IS, Walling M, et al. Methods of accurate localisation of non-palpable subdermal contraceptive implants. J Fam Plann Reprod Health Care. 2008;34(1):9-12.

52. Navani M, Robinson C. Clinical challenge with Implanon removal: a case report. J Fam Plann Reprod Health Care. 2005;31(2): 161-162.

53. Ismail H, Mansour D, Singh M. Migration of Implanon. J Fam Plann Reprod Health Care. 2006;32(3):157-159.

54. Pillai M, Gazet AC, Griffiths M. Continuing need for and provision of a service for non-standard implant removal. J Fam Plann Reprod Health Care. 2014;40(2):126-132.

55. Craik J, Rowlands S. Contraceptive devices for women: implants, intrauterine devices and other products. In: Harrison-Woolrych M, editor Medicines for women: a safety perspective. Springer. In press 2014.

56. Rowlands S, Sujan MA, Cooke M. A risk management approach to the design of contraceptive implants. J Fam Plann Reprod Health Care. 2010;36(4):191-195.

57. Rowlands S. Legal aspects of contraceptive implants. J Fam Plann Reprod Health Care. 2010;36(4):243-248.

58. Brown M, Britton J. Neuropathy associated with etonogestrel implant insertion. Contraception. 2012;86(5):591-593.

59. Hueston WJ, Locke KT. Norplant neuropathy: peripheral neurologic symptoms associated with subdermal contraceptive implants. $J$ Fam Pract. 1995;40(2):184-186.

60. Ernst U. The case of the missing implant: the importance of adhering to insertion guidelines. Eur J Contraception Reprod Health Care. Epub January 6, 2004

61. Agrawal A, Robinson C. Spontaneous snapping of an Implanon in two halves in situ. J Fam Plann Reprod Health Care. 2003;29(4):238.

62. Elliman A. Removal of a fractured Nexplanon ${ }^{\circledR}$. J Fam Plann Reprod Health Care. 2013;39(1):66-67.

63. Bentley J. Experience and removal of damaged implants. J Fam Plann Reprod Health Care. 2013;39(3):233-234.

64. Torres R, Mendes N, Machado AI, Marques C. In situ breakage of Implanon ${ }^{\circledR}$ - two cases of a rare occurrence. Contraception. 2013;88(1):189-191.

65. Tomás-Tello MD, Hodgson G. Two cases of broken Implanon $\left({ }^{\circledR}\right)$. J Fam Plann Reprod Health Care. 2010;36(4):255. 
66. Rekers H. Removal of a fractured Nexplanon ${ }^{\circledR}$ : MSD response. J Fam Plann Reprod Health Care. 2013;39(1):67.

67. Pymar HC, Creinin MD, Schwartz JL. "Pop-out" method of levonorgestrel implant removal. Contraception. 1999;59(6): 383-387.

68. Reynolds RD. The 'Modified U' technique: a refined method of Norplant removal. J Fam Pract. 1995;40(2):173-180.

69. Sivin I, Mishell DR Jr, Diaz S, et al. Prolonged effectiveness of Norplant ${ }^{\circledR}$ capsule implants: a 7-year study. Contraception. 2000; 61(3):187-194.

70. Lakha F, Glasier AF. Continuation rates of Implanon in the UK: data from an observational study in a clinical setting. Contraception. 2006;74(4):287-289.

71. Arribas-Mir L, Rueda-Lozano D, Agrela-Cardona M, CedeñoBenavides T, Olvera-Porcel C, Bueno-Cavanillas A. Insertion and 3-year follow-up experience of 372 etonogestrel subdermal contraceptive implants by family physicians in Granada, Spain. Contraception. 2009;80(5):457-462.

72. Harvey C, Seib C, Lucke J. Continuation rates and reasons for removal among Implanon users accessing two family planning clinics in Queensland, Australia. Contraception. 2009;80(6):527-532.

73. Teunissen AM, Grimm B, Roumen FJ. Continuation rates of the subdermal contraceptive Implanon ${ }^{\circledR}$ and associated influencing factors. Eur J Contracept Reprod Health Care. 2014;19(1):15-21.

74. Peipert JF, Zhao Q, Allsworth JE, et al. Continuation and satisfaction of reversible contraception. Obstet Gynecol. 2011;117(5):1105-1113.

75. O'neil-Callahan M, Peipert JF, Zhao Q, Madden T, Secura G. Twentyfour-month continuation of reversible contraception. Obstet Gynecol. 2013;122(5):1083-1091.
76. Short M, Dallay D, Omokanye S, Hanisch JU, Inki P. Acceptability of the levonorgestrel releasing-intrauterine system and etonogestrel implant: one-year results of an observational study. Eur J Contracept Reprod Health Care. 2012;17(1):79-88.

77. Short M, Dallay D, Omokanye S, Stauch K, Inki P. Acceptability of long-acting, progestin-only contraception in Europe: a two-year prospective, non-interventional study. Eur J Contracept Reprod Health Care. 2014;19(1):29-38.

78. Weisberg E, Bateson D, McGeechan K, Mohapatra L. A three-year comparative study of continuation rates, bleeding patterns and satisfaction in Australian women using a subdermal contraceptive implant or progestogen releasing-intrauterine system. Eur J Contracept Reprod Health Care. 2014;19(1):5-14.

79. Newton J, Newton P. Implanon ${ }^{\circledR}$ : the single-rod subdermal contraceptive implant. J Drug Eval. 2003;1:181-218.

80. Glasier A. Implantable contraceptives for women: effectiveness, discontinuation rates, return of fertility, and outcome of pregnancies. Contraception. 2002;65(1):29-37.

81. Mavranezouli I; LARC Guideline Development Group. The cost-effectiveness of long-acting reversible contraceptive methods in the UK: analysis based on a decision-analytic model developed for a National Institute for Health and Clinical Excellence (NICE) clinical practice guideline. Hum Reprod. 2008;23(6):1338-1345.

82. Lipetz C, Phillips CJ, Fleming CF. The cost-effectiveness of a long-acting reversible contraceptive (Implanon) relative to oral contraception in a community setting. Contraception. 2009;79(4): 304-309.
Open Access Journal of Contraception

\section{Publish your work in this journal}

Open Access Journal of Contraception is an international, peerreviewed, open access, online journal, publishing original research, reports, reviews and commentaries on all areas of contraception. In addition to clinical research, demographics and health-related aspects, the journal welcomes new findings in animal and preclinical studies

\section{Dovepress}

relating to understanding the biological mechanisms and practical development of new contraceptive agents. The manuscript management system is completely online and includes a very quick and fair peer-review system. Visit http://www.dovepress.com/testimonials.php to read real quotes from published authors. 